\title{
Roux-en-Y Gastric Bypass Improves Hepatic Glucose Metabolism Involving Down- Regulation of Protein Tyrosine Phosphatase 1B in Obese Rats
}

\author{
Song $\mathrm{Mu}^{\mathrm{a}}$ Jiayu Liu ${ }^{\mathrm{b}} \quad$ Wei Guo $^{\mathrm{a}}$ Shuping Zhang ${ }^{\mathrm{b}} \quad$ Xiaoqiu Xiao $^{\mathrm{c}}$ \\ Zhihong Wang ${ }^{\text {b JunZhang }}{ }^{\text {a }}$ \\ a Department of General Surgery, the First Affiliated Hospital of Chongqing Medical University, \\ Chongqing, China; ${ }^{\mathrm{b}}$ Department of Endocrinology, the First Affiliated Hospital of Chongqing \\ Medical University, Chongqing, China; ' Laboratory of Lipid \& Glucose Metabolism, The First \\ Affiliated Hospital of Chongqing Medical University, Chongqing, China
}

\section{Keywords}

Obesity · Gluconeogenesis · Glycogen synthesis · Roux-en-Y gastric bypass surgery · Protein tyrosine phosphatase $1 \mathrm{~B}$

\begin{abstract}
Objective: This study was initiated to investigate the effects of Roux-en-Y gastric bypass (RYGB) surgery on hepatic glucose metabolism and hepatic expression of protein tyrosine phosphatase 1B (PTP1B) in obese rats. Methods: Body weight, glucose, intraperitoneal glucose, insulin, and pyruvate tolerance tests were performed pre- and postoperatively, and plasma lipid, insulin and glucagon-like peptide 1 (GLP-1) were measured. The mRNA levels of G6Pase, Pepck, Gsk-3 $\beta$ and Gys-2, and the expression levels of PTP1B mRNA, protein, and other components of the insulin signaling pathway were measured by using RT-PCR and western blotting. The intracellular localization of PTP1B and hepatic glycogen deposition was also observed. Results: RYGB surgery-treated rats showed persistent weight loss, significantly improved glucose tolerance, pyruvate tolerance, and dyslipidemia, as well as increased insulin sensitivity, hepatic glycogen deposition and increased plasma GLP-1 in obese rats. RT-PCR analyses showed Pepck, G6Pase, and Gsk-3 $\beta$ mRNA to be significantly decreased, and Gys-2 mRNA to be significantly increased in liver tissue in the RYGB group $(p<0.05 \mathrm{vs}$. high-fat diet
\end{abstract}

Song Mu and Jiayu Liu contributed equally to this study, Dr. Jun Zhang and Dr. Zhihong Wang are cocorresponding authors. 
(HFD) or HFD + sham group); in addition, the expression of PTP1B were significantly decreased and insulin signaling were improved in the RYGB group ( $p<0.05$ vs. HFD or HFD + sham group). Conclusion: RYGB can improve hepatic glucose metabolism and down-regulate PTP1B in obese rats. An increased circulating GLP-1 concentration may be correlated with the effects following RYGB in obese rats.

(C) 2017 The Author(s)

Published by S. Karger $\mathrm{GmbH}$, Freiburg

\section{Introduction}

Obesity is a worldwide epidemic metabolic disease and is known as a critical risk factor for various chronic diseases, such as type 2 diabetes (T2D), hypertension, hyperlipidemia, and fatty liver disease [1]. It is reported that the number of individuals who are overweight and obese reached 2.1 billion in 2013, up from 857 million in 1980 [2].

Traditional treatment strategies, such as lifestyle intervention and pharmacotherapy, are unreliable and often do not achieve persistent results. Bariatric surgery is considered the most effective treatment for morbid obesity [3]. Among common bariatric procedures, Rouxen-Y gastric bypass (RYGB) surgery is considered the most effective procedure for producing long-term weight loss and metabolic improvement in obese patients. Glucose homeostasis has been reported to be improved prior to marked increases in weight loss and insulin sensitivity in both rodents and humans, particularly in the context of T2D [4, 5], suggesting that the benefit effects of RYGB may not completely depend on food restriction and malabsorption. Previous studies have shown that RYGB promotes the secretion of incretins, such as glucagonlike peptide 1 (GLP-1), and improves the metabolic homeostasis [6-9]. However, the specific mechanisms mediating these changes are still incompletely understood.

The liver is the main target organ involved in insulin-dependent maintenance of normal glucose homeostasis through inhibition of hepatic glucose production (HGP) [10]. Obesity is usually accompanied by insulin resistance and impairs the role of insulin in the regulation of HGP, thereby contributing to hyperglycemia in obese animals and humans [11]. He et al. [12] found that improving hepatic insulin sensitivity played a key role in remission of T2D in longterm studies. Previous studies have shown that RYGB can significantly reduce HGP by influencing hepatic gluconeogenesis and glycogen synthesis in type 2 diabetic rats $[13,14]$. In addition, Flynn et al. [15] demonstrated that RYGB could reduce hepatic gene expression relevant to lipid metabolism in diet-induced obesity (mice obviously. Hepatic gluconeogenic and glycolytic pathways are predominantly regulated by the transcription factor forkhead box 01 (Fox01), one of the major intracellular targets of insulin, through inhibition of transcriptional activation of relevant key enzymes [16, 17]. However, Akt-dependent Fox01 phosphorylation is selectively impaired in ob/ob mice with hepatic insulin resistance [18]. Furthermore, overexpression of Fox01 facilitates hepatic glucose production, indicating a critical role of Fox01 in the regulation of glucose homeostasis [19].

Protein tyrosine phosphatase 1B (PTP1B), a key negative regulator of the insulin signaling pathway, is widely expressed in insulin-sensitive tissues and is localized on the endoplasmic reticulum (ER) [20]. The physiological role of PTP1B in hepatic glucose homeostasis involves decreasing the phosphorylation of tyrosine residues in the insulin receptor and insulin receptor substrate (IRS) [21]. Several studies have shown that insulin sensitivity is enhanced in response to increased IRS1-mediated Akt/Foxo1 signaling in the liver and skeletal muscle of PTP1B-null mice. Moreover, PTP1B-deficient mice exhibit obvious suppression of HGP, enhancement of glucose disposal, and resistance to weight gain on a high-fat diet (HFD) [22]. 
Therefore, the effects on regulating glucose homeostasis as well as the influence of PTP1B following RYGB in obese rats may uncover a potentially important way for preventing and treating obesity. In this study, we performed RYGB surgery in HFD-induced obese rats to investigate the effects of RYGB on hepatic glucose metabolism and hepatic expression of PTP1B.

\section{Material and Methods}

\section{Animal and Model}

Male Sprague-Dawley (SD) rats (101.2 $\pm 12.3 \mathrm{~g})$ were provided by the Laboratory Animal Center of Chongqing Medical University and maintained under a 12-hour light/12-hour dark cycle at a constant temperature of $\left(22 \pm 2{ }^{\circ} \mathrm{C}\right)$. Water and food were provided ad libitum, except in experiments requiring fasting. All animal experiments conformed to the National Institutes of Health guidelines and were approved by the local ethics committee of Chongqing Medical University. 70 rats were randomly allocated to the normal control group (low-fat diet (LFD) group, $\mathrm{n}=8$ ) consuming a standardized diet (\#D12450B; $3.85 \mathrm{kcal} / \mathrm{g}, 10 \%$ from fat; Research Diets, New Brunswick, NJ, USA) and obesity modeling animal group ( $\mathrm{n}=62)$ for the HFD (\#D12451; $4.73 \mathrm{kcal} / \mathrm{g}$, 45\% from fat; Research Diets). Rats in the HFD group having body weights at least $20 \%$ higher than those in normal control rats were considered to be obese rats [23]. At the end of 13 weeks, 28 obese rats induced by HFD were randomly divided into three groups: obesity model group (HFD group, $n$ $=8$ ), sham Roux-en-Y gastric bypass group (HFD + sham group, $n=8$ ), and Roux-en-Y gastric bypass group (HFD + RYGB group, $n=12$ ). The HFD + sham group were re-anastomosed at the original transection site of small bowel. The HFD + RYGB group received transection and bypass surgery, while the LFD and HFD groups did not receive surgical intervention.

\section{Surgical Procedures}

In the HFD + RYGB group, the stomach was transected using surgical scissors, and the distal stomach was anastomosed with a hand-sewn suture. The gastric pouch was then connected to the jejunum to create a gastric pouch with approximately $5 \%$ of the volume of the stomach [24]. The small bowel was transected to produce a $15-\mathrm{cm}$ biliopancreatic limb, a $10-\mathrm{cm}$ Roux limb, and a 33-cm common channel. Gastro-jejunostomy and jejuno-jejunostomy were performed using interrupted sutures (PDS 6-0), and the muscle layer and skin were closed using 4-0 silk. Rats in the HFD + sham group underwent similar pre-operative and postoperative care as RYGB rats. Additionally, the incision in the gastrointestinal tract was performed as in RYGB rats; however, the incision was re-anastomosed at the original transection site. All rats with surgical procedure were anesthetized with $5 \%$ pentobarbital sodium solution $(50 \mathrm{mg} / \mathrm{kg})$ and injected intramuscularly with ceftriaxone $(100 \mathrm{mg} / \mathrm{kg})$ as a prophylactic antibiotic at the beginning; $0.25 \%$ bupivicaine $(0.5 \mathrm{ml})$ were used to alleviate postoperative pain, and normal saline $(50 \mathrm{ml} / \mathrm{kg})$ were used for fluid resuscitation before and after surgery. After surgery, animals were housed individually and fasted for $24 \mathrm{~h}$; body weight and food consumption were measured daily. Then the animals were allowed to eat a liquid diet and had access to water ad libitum for 2 days. At the 4th day, animals were allowed to eat regular chow to ensure adequate healing of the gastrointestinal anastamoses. At 8 weeks after surgery, all rats were sacrificed and the liver tissues were collected and stored at $-80^{\circ} \mathrm{C}$ for further analysis.

Intraperitoneal Glucose Tolerance Test (IPGTT) and Intraperitoneal Pyruvate Tolerance Test (IPPTT)

Rats were fasted for about $16 \mathrm{~h}$ before intraperitoneal injection of glucose $(2 \mathrm{~g} / \mathrm{kg}$ body weight) or sodium pyruvate $(2 \mathrm{~g} / \mathrm{kg}$ body weight) after 12 weeks of HFD consumption and at 5 weeks postsurgery. Blood samples were obtained via the tail vein before ( $0 \mathrm{~min})$ and at $15,30,60$, and $120 \mathrm{~min}$ after glucose or pyruvate administration to measure blood glucose levels using a glucometer (Roche Accu-Chek; Roche Diagnostics GmbH, Grenzach-Wyhlen, Germany).

\section{Insulin Tolerance Test (ITT)}

Rats were fasted for about $4 \mathrm{~h}$ before intraperitoneal injection of recombinant human insulin $(1 \mathrm{U} / \mathrm{kg}$ body weight) after 13 weeks of HFD consumption and at 6 weeks postsurgery. Blood samples were obtained via the tail vein before $(0 \mathrm{~min})$ and at $30,60,90$, and $120 \mathrm{~min}$ after insulin administration to measure blood glucose levels using a glucometer (Roche Accu-Chek). 
Mu et al.: Roux-en-Y Gastric Bypass Improves Hepatic Glucose Metabolism Involving Down-Regulation of Protein Tyrosine Phosphatase 1B in Obese Rats

Table 1. Sequences of primers used in this study

\begin{tabular}{|c|c|c|c|c|}
\hline Gene & Acc. number & Sequence $\left(5^{\prime} \rightarrow 3^{\prime}\right)$ & length, bp & Temperature, ${ }^{\circ} \mathrm{C}$ \\
\hline Pepck & NM_198780.3 & $\begin{array}{l}\text { forward CGCTGGATGTCAGAAGAGG } \\
\text { reverse }\end{array}$ & 378 & $\begin{array}{l}57.6 \\
56.5\end{array}$ \\
\hline G6pase & NM_013098.2 & $\begin{array}{l}\text { forward TCCGTGCCTCTGATAAA } \\
\text { reverse CCACGAAAGATAGCGAGA }\end{array}$ & 128 & $\begin{array}{l}51.9 \\
53.8\end{array}$ \\
\hline Gsk-3 $\beta$ & NM_032080.1 & $\begin{array}{l}\text { forward CCTGCCСТCTTCAACTTTACCA } \\
\text { reverse TGTCCACGGTCTCCAGCATTA }\end{array}$ & 152 & $\begin{array}{l}61.1 \\
61.2\end{array}$ \\
\hline Gys-2 & NM_013089.2 & $\begin{array}{l}\text { forward GAAGAGTTTGTCCGAGGCTGTC } \\
\text { reverse TGAAACACCCGAAACCAGAGAG }\end{array}$ & 133 & $\begin{array}{l}60.5 \\
61.6\end{array}$ \\
\hline Ptp1b & NM_012637.2 & $\begin{array}{l}\text { forward GAAACGGATGGTGGGTGGA } \\
\text { reverse CACACGTTGACCAGGAAGGG }\end{array}$ & 132 & $\begin{array}{l}60.8 \\
60.8\end{array}$ \\
\hline GAPDH & NM_017008.4 & $\begin{array}{l}\text { forward GCTGAGTATGTCGTGGAG } \\
\text { reverse TCT TCTGAGTGGCAGTGAT }\end{array}$ & 286 & $\begin{array}{l}54.6 \\
55.6\end{array}$ \\
\hline
\end{tabular}

\section{Quantitative RT-PCR}

Total RNA was extracted from liver tissue by using Trizol reagent (TaKaRa, Kusatsu, Japan) and converted into cDNA using a PrimeScript RT reagent kit (TaKaRa). Specific primers were synthesized and purchased by TaKaRa; the primer sequences are shown in table 1. Quantitative PCR analysis was performed with One Step SYBR Green (Bio-Rad, Hercules, CA, USA) in a RT-PCR apparatus (Applied Biosystems, Foster City, CA, USA). Each reaction was performed in triplicate. The delta-delta Ct method was used to determine the fold change for each group. The mRNA levels were quantified by normalization to GAPDH and expressed relative to the levels in the LFD group.

\section{Western Blotting}

Proteins were extracted from liver tissues, and the protein concentrations were determined using Enhanced BCA protein assays (Beyotime, Beijing, China). The proteins were isolated by electrophoresis on $8 \%$ or $10 \%$ sodium dodecyl sulfate polyacrylamide gels and transferred onto PVDF membranes (Millipore, Billerica; MA, USA). The membranes were blocked and then incubated with the following primary antibodies overnight at $4{ }^{\circ} \mathrm{C}$ : anti-Akt, anti-phospho-Akt, anti-IRS1, anti-phospho-IRS1, anti-Foxo1, anti-phospho-Foxo1 (1:1,000; Cell Signaling Technology, Danvers, MA, USA), anti-PTP1B (1:200; Santa Cruz Biotechnology, Santa Cruz, CA, USA), and anti- $\beta$-actin (1:5000; Proteintech, Rosemont, IL, USA). Membranes were then washed in Tris-buffered saline + Tween 20 and incubated with peroxidase-conjugated Affinipure goat anti-mouse $\operatorname{IgG}(\mathrm{H}+\mathrm{L})$ or anti-rabbit $\operatorname{IgG}(\mathrm{H}+\mathrm{L})$ (1:5,000; Proteintech) for $1.5 \mathrm{~h}$. Protein expression was detected using a Western Bright ECL kit (Advansta, Menlo Park, CA, USA). Densitometric analysis was performed using Quantity One software (Fusion-Capt, Marne-la-Vallée, France).

\section{Immunohistochemistry and Histopathological Examinations}

Paraffin-embedded liver tissues samples were sectioned into 5 - $\mu \mathrm{m}$-thick slices. After antigen recovery and blocking, the sections were incubated with anti-PTP1B antibodies (1:50; Santa Cruz Biotechnology) overnight at $4{ }^{\circ} \mathrm{C}$, followed by incubation with secondary antibodies (Zhongshan Golden Bridge Inc., Beijing, China) for $30 \mathrm{~min}$ at $37^{\circ} \mathrm{C}$. Sections were then stained with DAB (3,3'-diaminobenzidine) and counterstained with hematoxylin. A Nikon Eclipse 80i microscope (Tokyo, Japan) was used to visualize the expression and intracellular localization of PTP1B. The sections also were stained with hematoxylin and eosin (H\&E) or Periodic Acid-Schiff (PAS) in accordance with routine techniques. Dual X-ray absorptiometry (DEXA) was used to determine body composition in each group. 
Mu et al.: Roux-en-Y Gastric Bypass Improves Hepatic Glucose Metabolism Involving Down-Regulation of Protein Tyrosine Phosphatase 1B in Obese Rats

Table 2. Changes in plasma levels of biochemical indexes in each group of rats (mean $\pm S D, n=6$ )

\begin{tabular}{lllll}
\hline & LFD & HFD & HFD + sham & HFD + RYGB \\
\hline ALT, U/l & $50.53 \pm 10.80$ & $53.93 \pm 12.84$ & $54.75 \pm 10.96$ & $60.35 \pm 15.68$ \\
AST, U/l & $112.5 \pm 15.97$ & $121.9 \pm 14.35$ & $125.1 \pm 16.69$ & $137.7 \pm 19.98$ \\
Total cholesterol, mmol/l & $1.92 \pm 0.27$ & $2.63 \pm 0.34^{*}$ & $2.58 \pm 0.43$ & $2.09 \pm 0.28 \#$ \\
Triglycerides, mmol/l & $1.14 \pm 0.32$ & $1.73 \pm 0.38^{*}$ & $1.94 \pm 0.44$ & $1.34 \pm 0.36 \#$ \\
HDL-C, mmol/l & $1.42 \pm 0.16$ & $1.29 \pm 0.23$ & $1.24 \pm 0.20$ & $1.37 \pm 0.19$ \\
LDL-C, mmol/l & $2.02 \pm 0.47$ & $2.68 \pm 0.38^{*}$ & $2.59 \pm 0.37$ & $2.16 \pm 0.29 \#$ \\
HOMA-IR & $8.85 \pm 1.68$ & $14.90 \pm 1.71^{*}$ & $15.47 \pm 2.62$ & $9.91 \pm 1.02 \#$ \\
\hline
\end{tabular}

${ }^{*} \mathrm{p}<0.05$ compared with the LFD group; ${ }^{\#} \mathrm{p}<0.05$ compared with HFD group and the HFD + sham group.

\section{Blood Biochemical Analysis}

All rats were fasted overnight, and the blood samples were collected from the angular vein and centrifuged at 3,000 rpm for $10 \mathrm{~min}$ at $4{ }^{\circ} \mathrm{C}$ for analysis of alanine transaminase (ALT), aspartate transaminase (AST), and plasma lipid profiles using an automatic analyzer Vitros5.1 FS (Ortho-Clinical Diagnostics, Inc., Raritan, NJ, USA). Plasma insulin and GLP-1 levels were measured using commercially available enzymelinked immunosorbent assay (ELISA) kits (Assay Biotech, Sunnyvale, CA, USA) in accordance with the manufacturer's instructions. Homeostasis model assessment of insulin resistance (HOMA-IR) scores were calculated as the fasting blood glucose level multiplied by the serum insulin level divided by 22.5 [25].

\section{Statistical Analysis}

All data were analyzed using SPSS 19.0 software (IBM Corp., Armonk, NY, USA) and were expressed as means \pm standard deviations (SDs). One-way analysis of variance were used to determine differences among treatment groups. Linear regression analysis was performed to determine the relationship between PTP1B and HOMA-IR or plasma GLP-1 levels. Differences or associations with p values of less than 0.05 were considered statistically significant.

\section{Results}

\section{HFD-Induced Obesity and Glucose Intolerance in Rats}

As expected, SD rats fed an HFD for 12 weeks gained more weight than control rats fed an LFD (fig. 1A). Rats in the HFD group exhibited obvious glucose intolerance (fig. 1B) and reduced insulin sensitivity (fig. 1D, table 2). The areas under the curve (AUCs) of GTT and ITT were increased by $21 \%$ and $24 \%$, respectively, compared with those in rats of the LFD group (fig. 1C,E). After 20 weeks of HFD consumption, the plasma levels of triglycerides, total cholesterol, and low-density lipoprotein cholesterol (LDLC) were increased, whereas high-density lipoprotein cholesterol (HDLC) levels were not significantly decreased. Additionally, HOMA-IR values were increased compared with those in rats fed an LFD (table 2).

\section{Effects on Body Weight, Adiposity, and Hepatic Glycogen Accumulation Following RYGB in}

\section{Obese Rats}

In our study, the rate of perioperative mortality was 33\% for RYGB surgery. The main causes of death were gastrointestinal anastomotic leak, intestinal ischemia necrosis, and bowel obstruction. No rats died in the HFD + sham group. There were 8 rats in each group at the endpoint for the subsequent analysis. RYGB caused $17 \%$ weight loss, while sham surgery only caused 3.8\% weight loss in rats fed an HFD at the second week after surgery (fig. 2A). At the end of the study period, the body weights of rats subjected to RYGB had decreased by $15 \%$, whereas those in rats subjected to sham surgery had increased by $8.2 \%$ (fig. $2 \mathrm{~A}, \mathrm{~B}$ ). To 


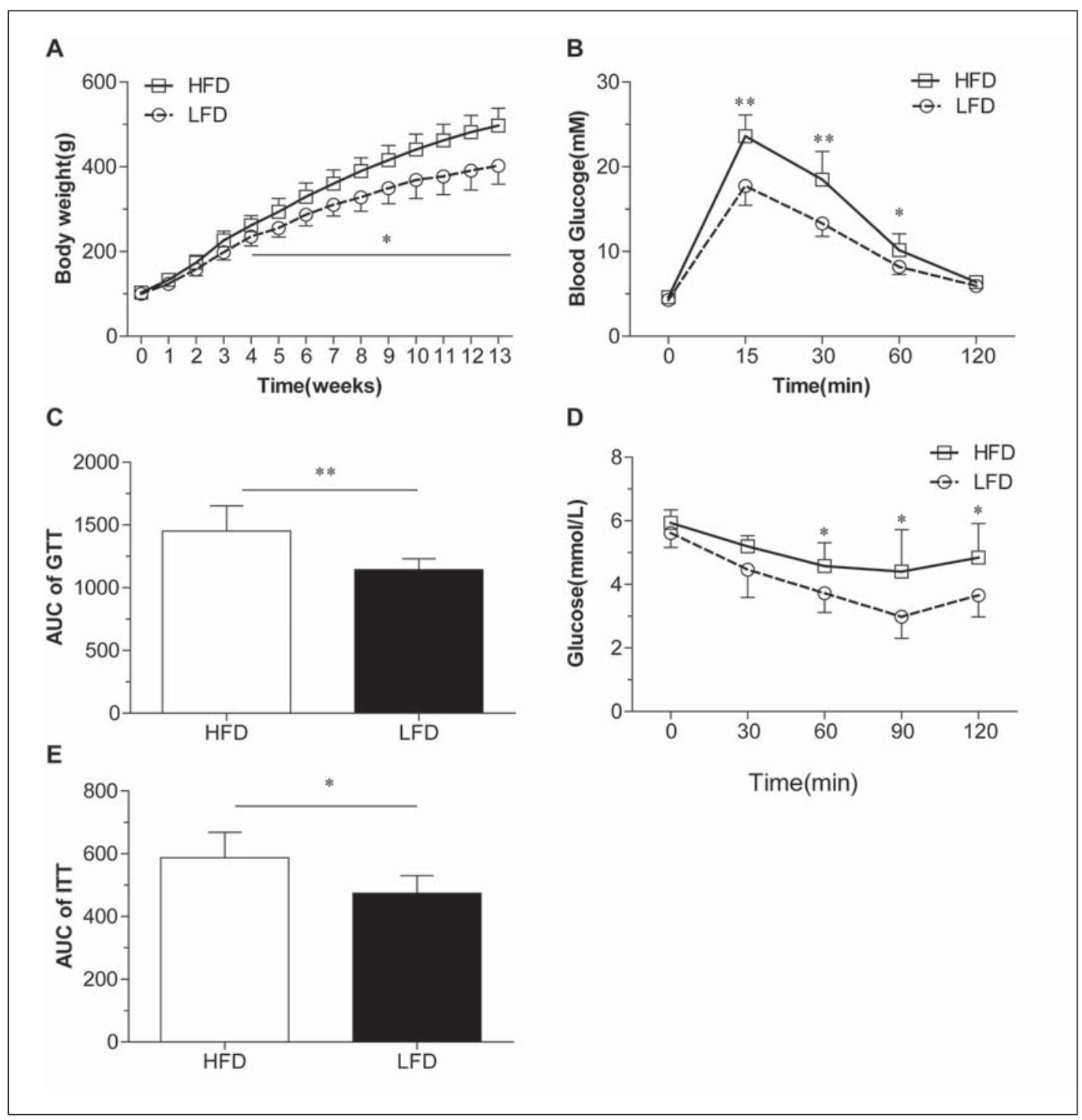

Fig. 1. HFD-induced obesity and glucose intolerance in rats. Changes in body weight in LFD (n = 8) and HFD $(n=28)$ groups $(\mathbf{A})$ was recorded every week. GTTs $(n=5)(\mathbf{B}$ and $\mathbf{C})$ and ITTs) $(n=5$; $\mathbf{D}$ and $\mathbf{E})$ were performed at 12 and 13 weeks of HFD consumption, respectively. Data are presented as mean \pm SD, $* \mathrm{p}<0.05$ and ${ }^{* *} \mathrm{p}<0.01$ compared with the LFD group.

examine the effects of RYGB on body composition after surgery, we performed DEXA analysis in each of the groups. As shown in figure 2C,D, the body fat ratio in the HFD and HFD + sham groups was markedly increased compared with that in rats of the LFD group $(25.6 \pm 4.3 \%$, $22.8 \pm 3.3 \%$ vs. $17.9 \% \pm 4.1 \%$ ) and was dramatically decreased to $14.4 \% \pm 4.11 \%$ at the 8 weeks after RYGB surgery ( $\mathrm{p}<0.05)$. We also collected epididymal fat samples in each group and found that the fat mass was significantly decreased after RYGB (fig. 2E). Similarly, H\&E staining of liver tissues showed signs of hepatic steatosis in obese rats; RYGB appears to alleviate these symptoms (fig. 3F). Furthermore, the parameters of the lipid metabolism (triglycerides, total cholesterol, and LDL-C) were markedly decreased after RYGB surgery ( $<<0.05)$, while the HDL-C level in RYGB group was not significantly different after surgery compared 
with the other three groups (table 2). Taken together, these data suggest that RYGB could produce sustained substantial weight loss and significantly reduce adiposity and dyslipidemia in obese rats.

Effects on Glucose Homeostasis and Insulin Sensitivity Following RYGB in Obese Rats

As shown in figure 3A, non-fasting blood glucose levels were permanently decreased at 2 weeks and close to the LFD group at 4 weeks after RYGB, while sham surgery did not induce these significant changes. Moreover, fasting glucose levels were decreased by $12 \%$ in rats in the HFD-RYGB group compared with those of rats in the HFD and HFD + sham groups ( $\mathrm{p}<$ 0.05 ) (fig. 3B). Rats in the HFD-RYGB group exhibited lower blood glucose at 15,30 or $60 \mathrm{~min}$ following GTT and ITT compared with those in the HFD + sham group ( $<<0.05)$ (fig. 3C-F). In addition, we calculated HOMA-IR as an indicator of insulin sensitivity and found that HOMA-IR scores in obese rats were significantly decreased after RYGB compared with those of rats in the HFD and HFD + sham groups $(p<0.05)$ (table 2). Fasting plasma insulin levels were significantly increased in obese rats compared with those in the LFD group and significantly decreased after RYGB when compared with the HFD and HFD + sham groups (fig. 3G). In addition, fasting plasma GLP-1 levels in the HFD and HFD + sham groups were significantly decreased compared with that in the LFD group, and were dramatically increased in the RYGB group in comparison with those in the HFD and HFD + sham groups (fig. $3 \mathrm{H}$ ). These data suggest that glucose intolerance and insulin resistance were significantly ameliorated in obese rats after RYGB surgery.

Inhibition of Gluconeogenesis and Promotion of Glycogen Synthesis in the Liver Following $R Y G B$ in Obese Rats

PTTs reflect changes in hepatic glucose production [26]. Therefore, we performed PTTs and found that pyruvate tolerance was dramatically improved by RYGB, but not by sham surgery, in obese rats ( $\mathrm{p}<0.05$ ) (fig. 4A,B). Furthermore, PAS staining of liver tissue showed a significant reduction in glycogen storage in the HFD and HFD + sham groups compared with LFD group, while it dramatically increased in the HFD + RYGB group after surgery (fig. 2G). Next, we examined the effects of RYGB on the expression levels of genes related to gluconeogenesis and glycogen synthesis. The mRNA levels of hepatic Pepck, G6pase, and Gsk-3 $\beta$ in the HFD and HFD + sham groups were significantly higher than those in the LFD group, but these levels showed a substantial decrease in the HFD + RYGB group compared with the HFD and HFD + sham groups at the end of this study (fig. 4C-E). However, the mRNA levels of Gys-2 in the HFD and HFD + sham groups were significantly lower than those in the LFD group, while the Gys-2 mRNA level apparently increased in the HFD + RYGB group compared with the HFD and HFD + sham groups at the end of this study (fig. 4F). These results suggested that RYGB improved glucose homeostasis through inhibition of gluconeogenesis and promotion of glycogen synthesis.

\section{Effects on the Expression of PTP1B and Insulin Signaling Components in Liver Following}

RYGB in Obese Rats

PTP1B has been recognized as a critical negative regulator of the leptin and insulin signaling pathways [20]. Thus, we examined PTP1B expression to determine the effects of RYGB surgery in the liver in our model. The PTP1B mRNA and protein levels in the HFD and HFD + sham groups were significantly higher than those in the LFD group (fig. $5 \mathrm{~A}-\mathrm{C}$ ), while they were apparently decreased in the HFD + RYGB group compared with those in the HFD and HFD + sham groups (fig. $5 \mathrm{~A}-\mathrm{C}$ ). These changes in the patterns of PTP1B protein expression were further confirmed by immunohistochemical analysis showing that PTP1B protein was predominantly localized in the cytoplasm (fig. 5D). As it is well known that PTP1B is an 
A

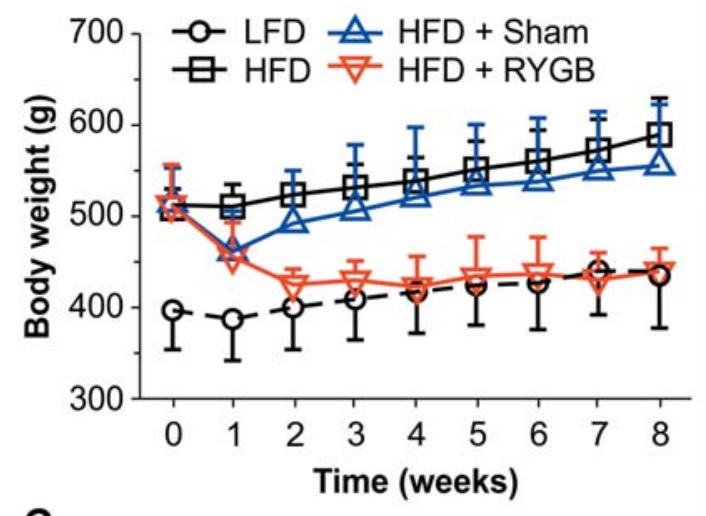

B

C
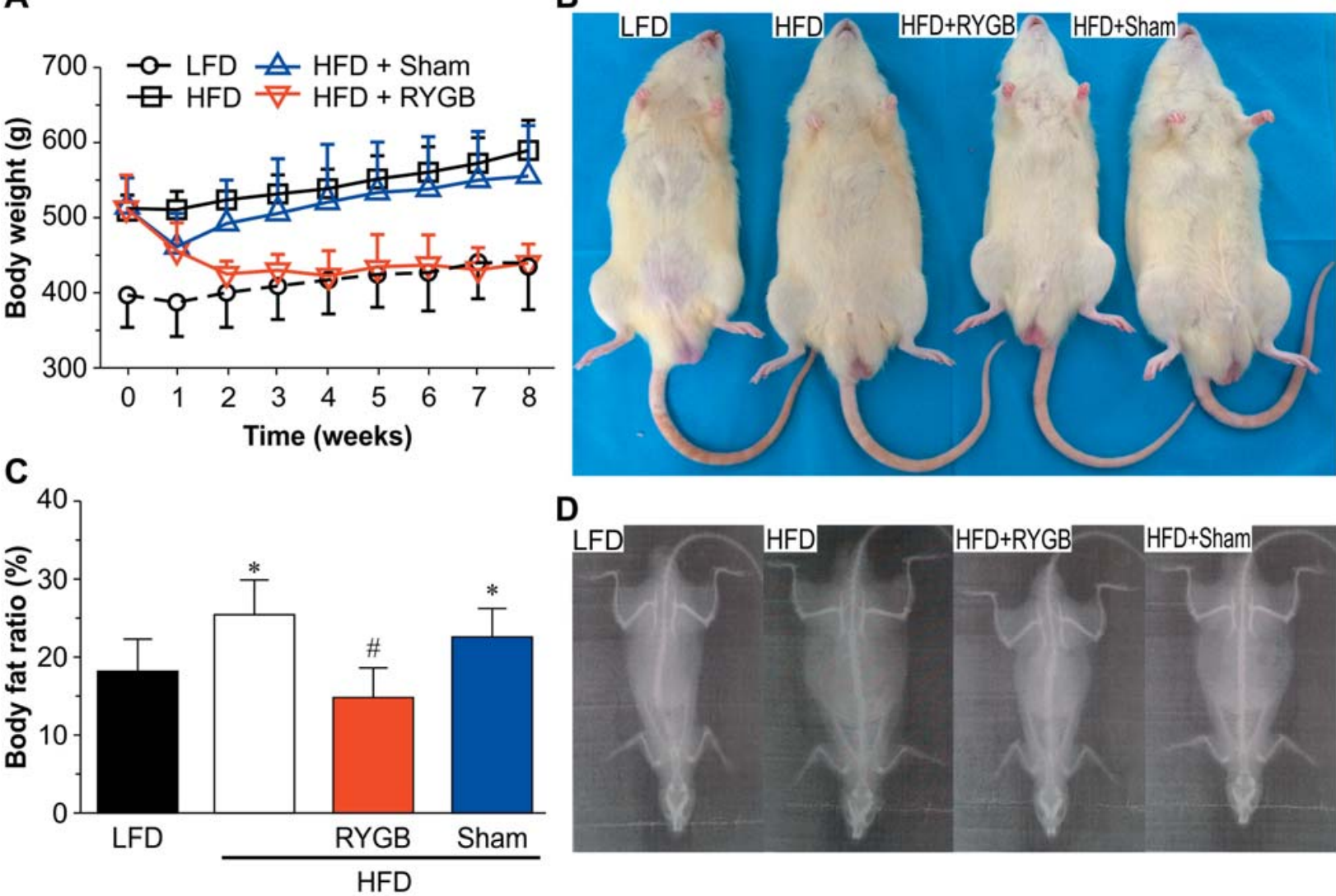

D

E

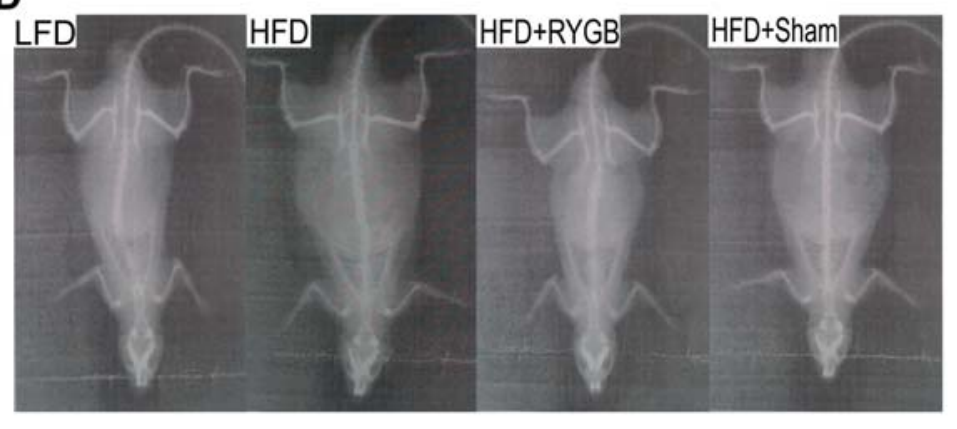

LFD
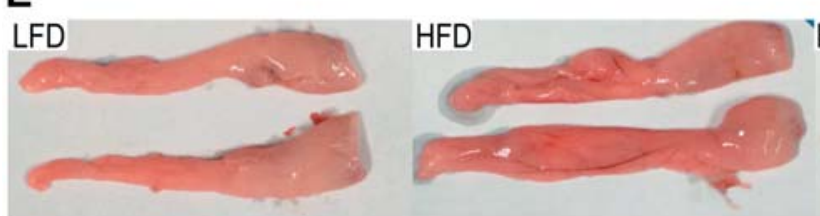

'HFD+RYGB

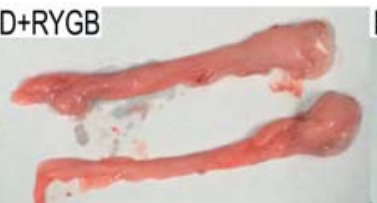

HFD+Sham

$\mathbf{F}$
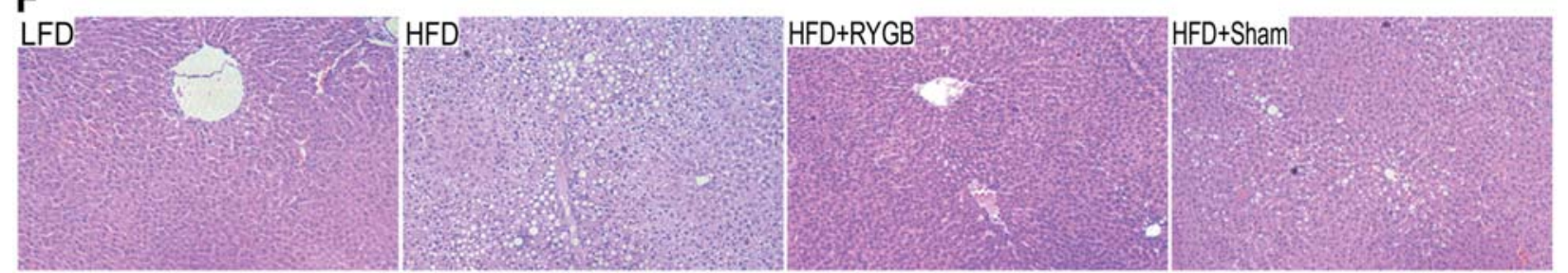

G

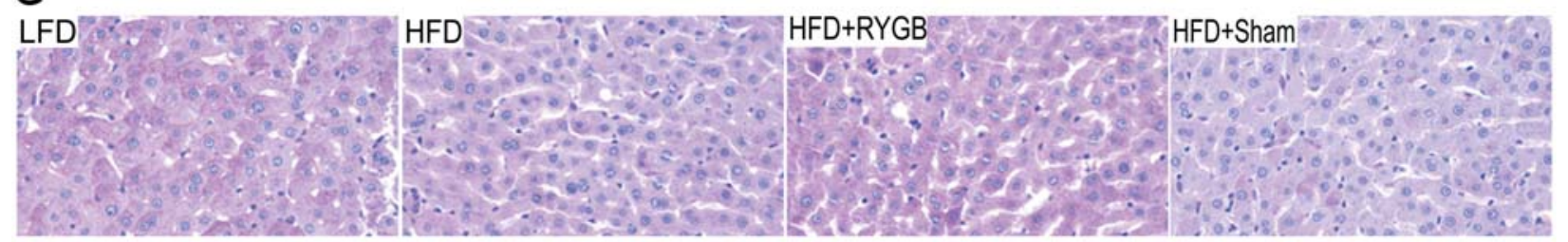


Mu et al.: Roux-en-Y Gastric Bypass Improves Hepatic Glucose Metabolism Involving Down-Regulation of Protein Tyrosine Phosphatase 1B in Obese Rats

important negative regulator of insulin signaling in vivo, we next examined the insulin signaling pathway, and the results showed that the phosphorylation of IRS1, Akt, and Foxo1 in the HFD and HFD + sham groups was significantly lower than those in the LFD group; Compared to the HFD and HFD + sham groups, the phosphorylation of IRS1, Akt, and Foxo1 was significantly increased in the HFD +RYGB group (fig. 5B,C). Additionally, there was a strong negative correlation between plasma GLP-1 levels and PTP1B protein expression $\left(r^{2}=0.395 ; p=0.005\right)$ and a strong positive association between HOMA-IR scores and PTP1B expression $\left(r^{2}=0.348 ; p=0.010\right)$ in liver tissue.

\section{Discussion}

Human observations and animal studies have demonstrated that RYGB surgery leads to long-term weight loss and metabolic improvement in obese subjects. Interestingly, RYGB surgery improves T2DM in glucose homeostasis by enhancing insulin sensitivity and reducing hepatic glucose output, even before significant weight loss is achieved [27]. Therefore, exploring the molecular pathways through which RYGB exerts its beneficial effects would facilitate the continued development of noninvasive anti-obesity therapies to complement the therapeutic effects of surgery.

HOMA-IR [25] is widely applied to measure insulin sensitivity and islet beta cell function. In this study, we used the HOMA-IR to confirm the hypothesis that insulin resistance was improved following RYGB in obese rats and found that HOMA-IR scores were nearly doubled in HFD-fed rats compared with those in control rats; importantly, this effect was reversed following RYGB surgery. Additionally, glucose intolerance, insulin resistance, and hepatic lipid content were significantly reduced in obese rats after RYGB. These results demonstrated that RYGB could effectively improve the systemic glucose homeostasis and dyslipidemia of these obese rats.

PTP1B has been implicated as a negative regulator of the insulin signaling pathway. Biochemical, genetic, and pharmacological studies have shown that PTP1B dephosphorylates the auto-phosphorylated insulin receptors and IRSs, serving as a molecular brake to suppress insulin signaling $[22,28,29]$. Clinical data have also shown that there is a close association between PTP1B variants and the prevalence of obesity or T2DM [30]. Thus, PTP1B may be a potential drug target for the enhancement of insulin sensitivity in obese patients or patients with T2DM [30, 31]. In the present study, we found that in obese rats the expression of PTP1B was significantly decreased following RYGB , and this decrease in PTP1B expression was well correlated with HOMA-IR scores. Our findings suggest that changes in hepatic PTP1B expression following RYGB in the obese rats are involved in the improvement of systemic glucose homeostasis.

Despite these findings, the exact mechanisms through which bariatric surgery ameliorates hepatic insulin resistance are still unclear. Hepatic glucose metabolism is mainly regulated by insulin. Insulin binds to insulin receptors and subsequently induces the phosphorylation of IRSs and the activation of the phosphoinositol 3-kinase(PI3K)-AKT signaling

Fig. 2. Effects on body weight, adiposity and hepatic glycogen accumulation following RYGB in obese rats. A Changes in body weight after surgery $(n=8)$. B Representative body appearance of rats at the endpoint. C Quantified body fat composition based on DEXA analysis ( $=3)$. D Representative DEXA image of rats at the endpoint. E Epididymal adipose tissues. F H\&E staining of liver tissue (original magnification, 100×). GPAS staining for hepatic glycogen content (original magnification, $400 \times$ ). Data are presented as mean \pm SD, ${ }^{*} \mathrm{p}<0.05$ compared with the LFD group; ${ }^{*} \mathrm{p}<0.05$ compared with the HFD group and the HFD + sham group. 
A

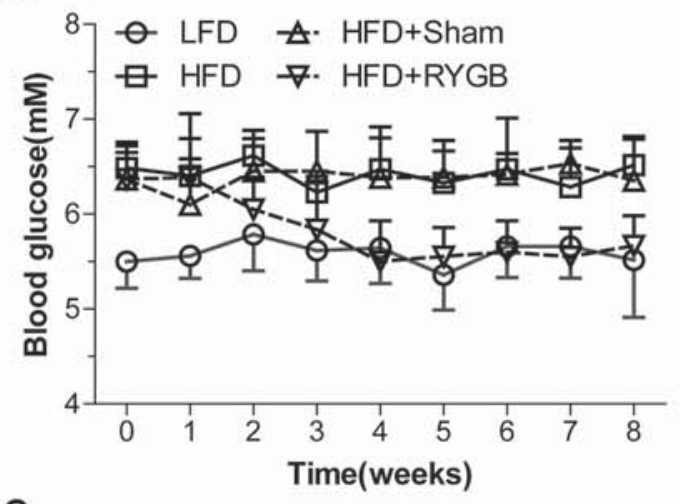

C

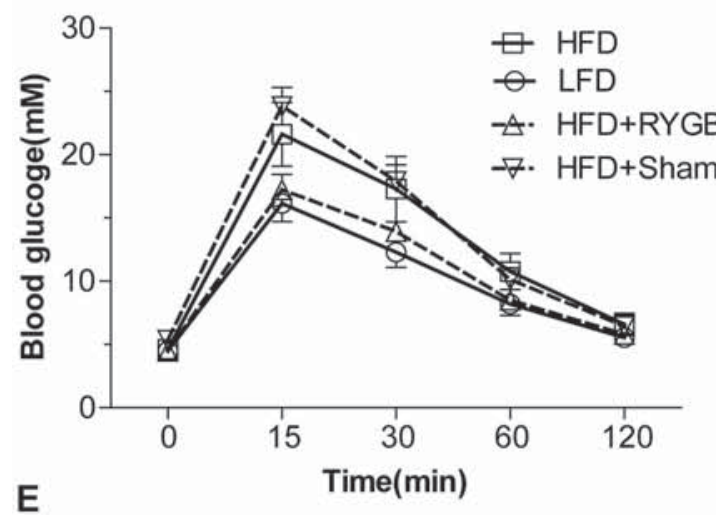

E

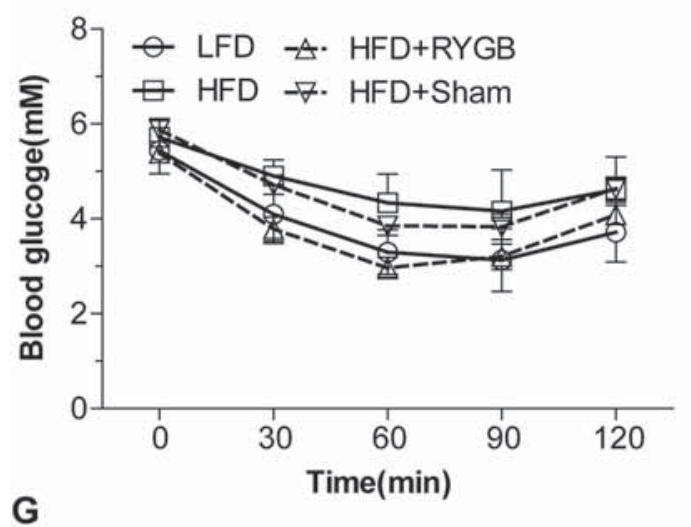

G

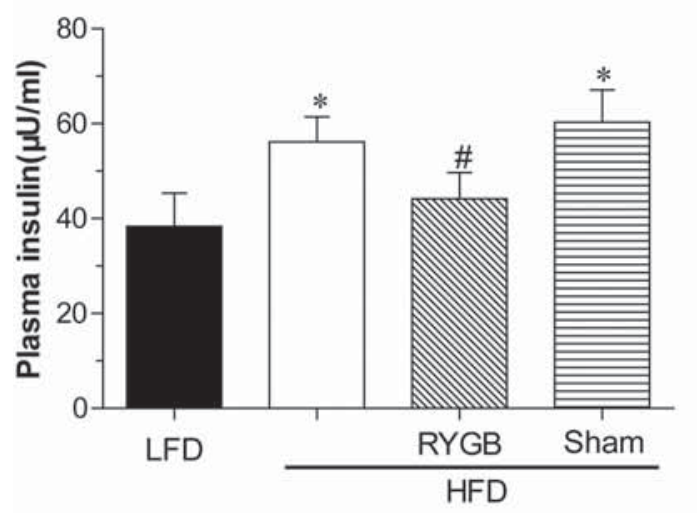

B

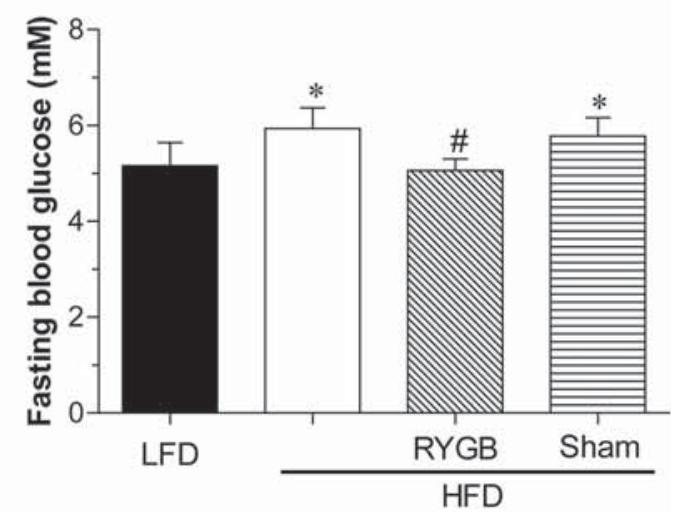

D
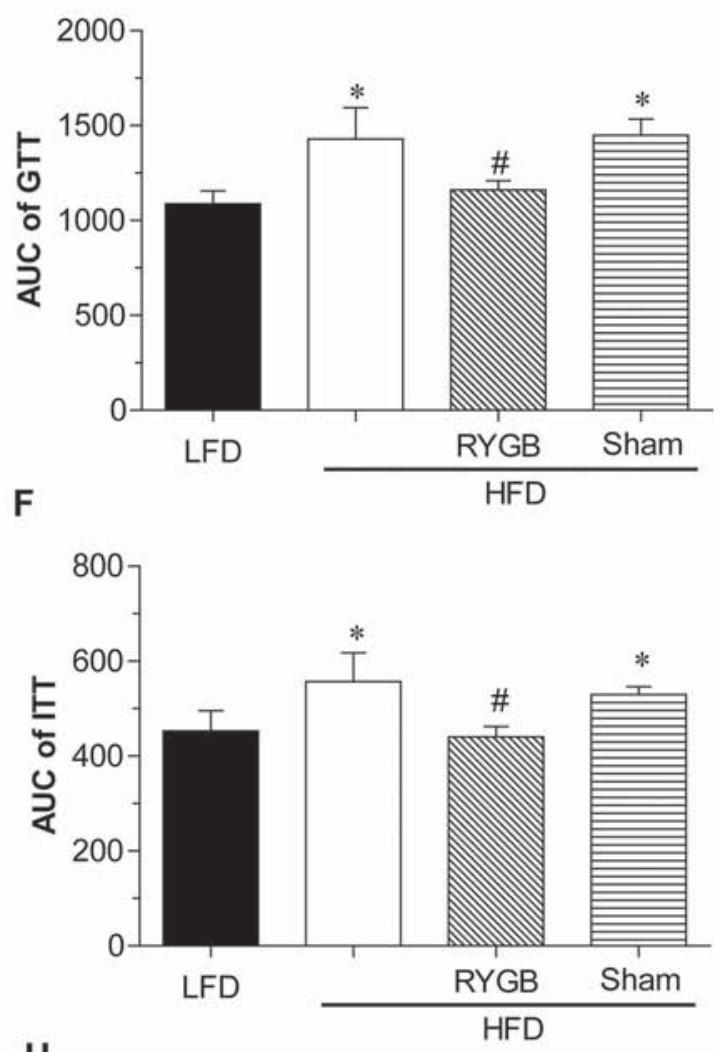

H

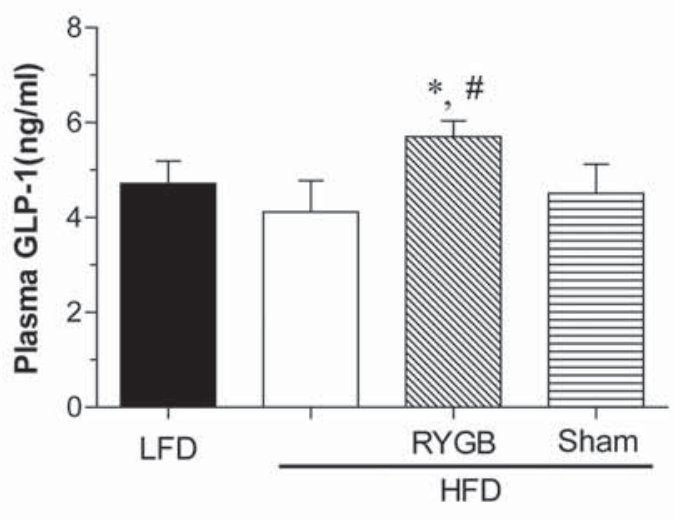


pathway. As a major mediator of the effects of insulin, the PI3K-AKT pathway promotes glycogen synthesis and stimulates glucose transport [32]. Gsk-3 $\beta$ is phosphorylated and inactivated by PI3K-AKT activation, subsequently preventing the phosphorylation of glycogen synthase and increasing glycogen content in the liver [33]. Simultaneously, PI3K-AKT activation phosphorylates Foxo1 proteins and decreases the expression of gluconeogenic genes, such as Pepck and G6pase [16]. Sun et al. [34] found that duodenal-jejunal bypass could significantly downregulate the expression of the key regulatory enzymes of hepatic gluconeogenesis without weight loss in diabetic GK rats. However, Gerhard et al. [35] reported that hepatic $G S$ gene expression and glycogen content were not different between nondiabetic and diabetic patients, and no remission were observed in patients with diabetes after RYGB. This is supposed to be due to the dysregulated FGF19-CYP7A1-BA pathway in diabetic patients. In the present study, we found that Pepck and G6pase gene expression were significantly decreased in obese rats following RYGB and caused improvement of pyruvate tolerance. Moreover, glycogen deposition was enhanced, Gsk-3 $\beta$ expression was decreased, and Gys-2 expression was increased in rats in the HFD +RYGB group compared with the HFD and the HFD + sham groups. Thus, these results indicated that hepatic glucose metabolism in obese rats was significantly improved following RYGB through reduction of gluconeogenesis and enhancement of glycogen synthesis. The role of PTP1B in various metabolic states has been further confirmed by genetic deletion of $P T P 1 B$ in mice, and it resulted in resistance to weight gain, increased energy expenditure, and retention of insulin sensitivity, even when consuming an HFD $[22,36]$. In addition, PTP1B can also terminate leptin signal transduction by dephosphorylating JAK2 [37]. In this study, we showed that chronic HFD consumption upregulated the expression of PTP1B in obese rats, while it was significantly reversed after RYGB. Moreover, the hepatic insulin signaling pathway was impaired in obese rats, as shown by decreased phosphorylation of IRS-1, Akt, and Foxo1. These effects were ameliorated following RYGB, restoring the activation of these proteins as shown in previous studies [5]. Our data indicated that reduced hepatic PTP1B expression in obese rats following RYGB may closely related to the amelioration of hepatic insulin resistance.

Previous studies suggested that the effects of RYGB on glucose metabolism may be explained by altered secretion of gastrointestinal peptides, such as GLP-1 [33]. As an incretin, GLP-1 is released from L cells of the small intestine becoming physiologically active by the activation of GLP-1 receptors [38]. Glucose homeostasis has been shown to be tightly regulated by GLP-1, and continuous infusion with a potent GLP-1 receptor antagonist was shown to disrupt glucose tolerance [39]. Liraglutide, a long-acting GLP-1 analogue, has been shown to attenuate myofibril and mitochondria injury in skeletal muscle of patients with T2DM through PTP1B and the PI3K/Akt signaling pathway [40]. Moreover, Kanoski et al. [41] reported that liraglutide reduces the expression of PTP1B, which could explain the effects of this compound on the enhancement of STAT3 phosphorylation after liraglutide-leptin co-administration. Our study showed that plasma GLP-1 levels in RYGB group rats were significantly higher than those in the HFD and HFD + sham groups. Additionally, we found that PTP1B expression was correlated with plasma GLP-1 levels. Thus, these results suggest that increased GLP-1 levels are associated with the metabolic changes after RYGB in obese rats.

Fig. 3. Effects on hepatic glucose homeostasis and insulin resistance following RYGB in obese rats. A Nonfasting blood glucose levels. B Fasting blood glucose levels at 8 weeks after surgery. C and D GTTs were performed at 5 weeks after surgery. $\mathbf{E}$ and $\mathbf{F}$ IITTs were performed at 6 weeks after surgery. $\mathbf{G}$ Plasma insulin levels. H Plasma GLP-1 levels. Data are presented as means \pm SD ( $n=8$ for A, B, G and H; $n=5$ for C-F). * $<<$ 0.05 compared with the LFD group; ${ }^{*} \mathrm{p}<0.05$ compared with the HFD group and the HFD + sham group. 


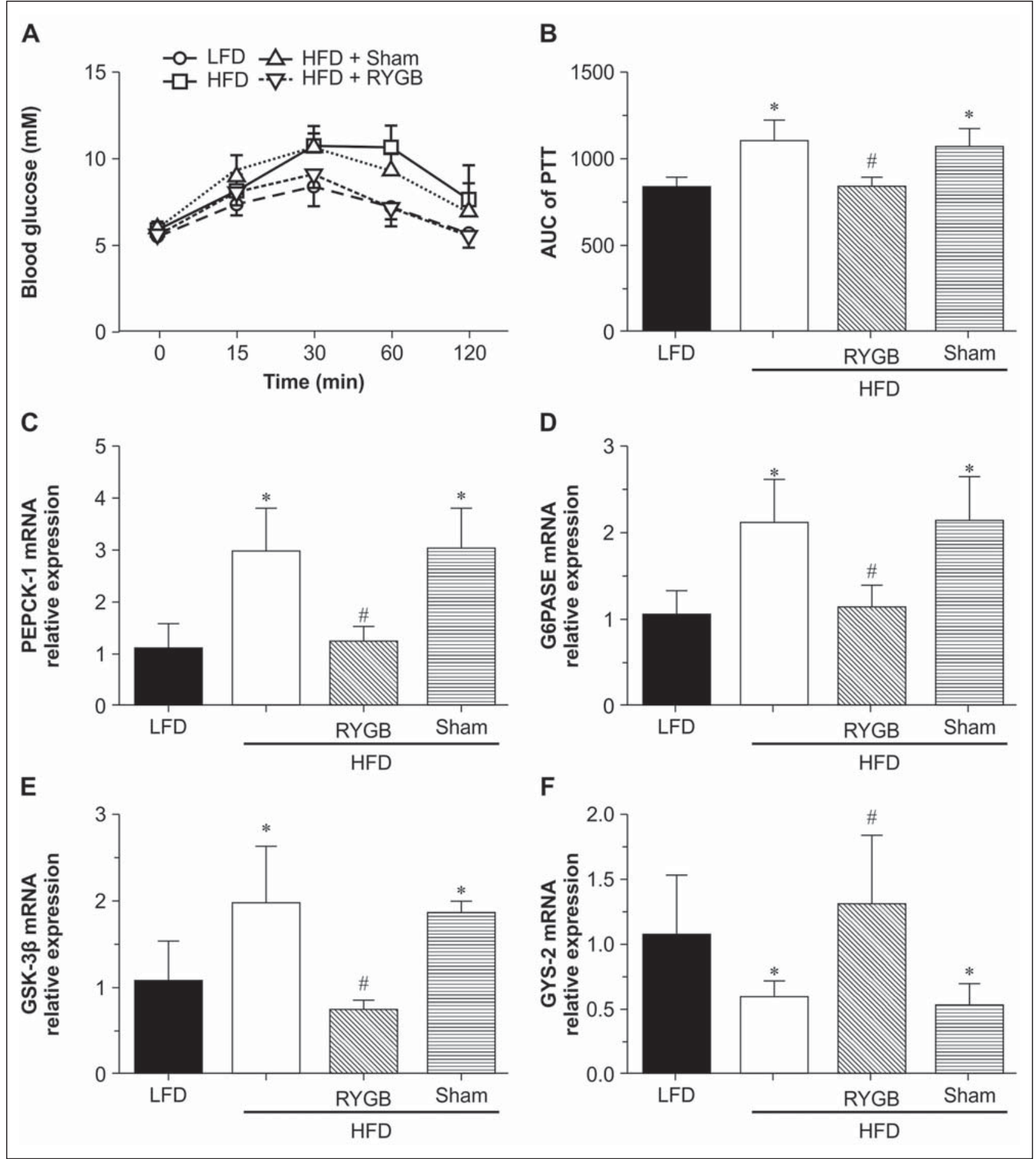

Fig. 4. Inhibition of gluconeogenesis and promotion of glycogen synthesis in the liver following RYGB in obese rats. A and B Intraperitoneal PTTswere performed at 5 weeks after surgery $(n=5)$. C-F Quantitative RT-PCR was used to analyze the mRNAs levels of Pepck, G6pase, Gsk-3 $\beta$, and Gys-2 ( $\mathrm{n}=8)$. Data are presented as means \pm SD. ${ }^{*} \mathrm{p}<0.05$ compared with the LFD group; ${ }^{*} \mathrm{p}<0.05$ compared with the HFD group and the HFD + SHAM group. 


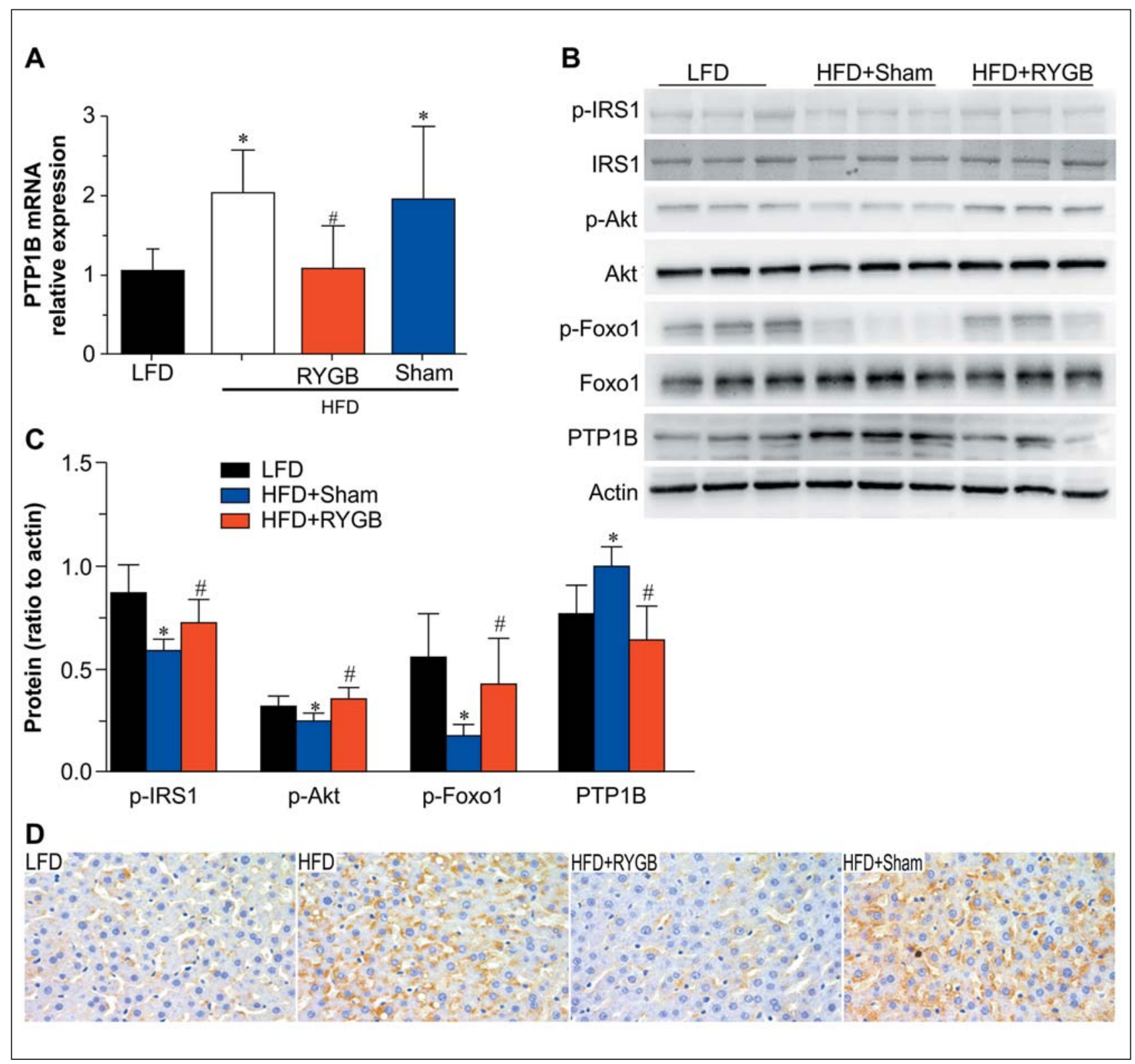

Fig. 5. Effects on the expression of PTP1B and insulin signaling components in the liver following RYGB in obese rats. A Quantitative RT-PCR was used to analyze the mRNA levels of PTP1B in the liver $(\mathrm{n}=8)$. B Western blotting of PTP1B and components of the insulin signaling pathway in the liver. C Quantification of western blotting results $(n=6)$. D Immunohistochemical staining was used to determine the intracellular localization and expression of PTP1B in the liver (original magnification, 400×). Data are presented as means \pm SD. * $<0.05$ compared with the LFD group; ${ }^{*}$ p $<0.05$ compared with the HFD group and the HFD + sham group.

However, our study has several limitations. Although the relative mRNA expression of Pepck, G6Pase, Gsk-3 $\beta$, and Gys-2 generally reflect their protein expression, we did not measure their protein expression. Secondly, we did not model a body weight-matched group to address the particular mechanism of RYGB on obesity. Nevertheless, compared to the HFD and HFD + sham groups, the decreased expression of PTP1B in the livers of RYGB-treated obese rats is 
associated with improved glucose homeostasis and insulin sensitivity following RYGB surgery. Despite its limitations, our study provides important information with respect to the effects of obesity and RYGB on PTP1B and hepatic glucose metabolism.

In summary, RYGB could inhibit gluconeogenesis, promote hepatic glycogen synthesis, ameliorate metabolic disturbances such as dyslipidemia, and increase insulin sensitivity by reducing adiposity and losing weight in obese rats. The improvement of hepatic glucose metabolism and downregulation of PTP1B in obese rats following RYGB provided a new way of thinking on prevention and treatment of obesity. Increased circulating GLP-1 concentrations might be correlated with the effects following RYGB in obese rats, but further studies concerning the particular mechanisms has to be awaited.

\section{Acknowledgments}

This study was supported by the National Key Clinical Specialist Construction Program of China (2011: Department of Endocrinology; 2012: Department of General Surgery), the Natural Science Foundation of Chongqing (CSTC2012jjA10040), The Tackling Project of Science and Technology of Chongqing Committee of Science and Technology (CSTC2012ggyyjs10038), the General Program of Chongqing Municipal Health Bureau (2011-2-062), and the Young and Middle-Age High-Level Medical Reserved Personnel Training Project Foundation of Chongqing, China. Yuweiren (2015) 49.

\section{Disclosure Statement}

The authors declare that they have no conflicts of interest concerning this article.

\section{References}

1 Martin-Rodriguez E, Guillen-Grima F, Marti A, Brugos-Larumbe A: Comorbidity associated with obesity in a large population: the APNA study. Obes Res Clin Pract 2015;9:435-447.

$2 \mathrm{Ng}$ M, Fleming T, Robinson M, et al: Global, regional, and national prevalence of overweight and obesity in children and adults during 1980-2013: a systematic analysis for the global burden of disease study 2013. Lancet 2014;384:766-781.

3 Kleinman NL, Melkonian A, Borden St, Rohrbacker N, Lynch WD, Gardner HH: The impact of morbid obesity and bariatric surgery on comorbid conditions: a comprehensive examination of comorbidities in an employed population. J Occup Environ Med 2009;51:170-179.

4 Abegg K, Corteville C, Docherty NG, Boza C, Lutz TA, Munoz R, le Roux CW: Effect of bariatric surgery combined with medical therapy versus intensive medical therapy or calorie restriction and weight loss on glycemic control in Zucker diabetic fatty rats. Am J Physiol Regul Integr Comp Physiol 2015;308:R321-329.

5 Rubino F, Gagner M, Gentileschi P, Kini S, Fukuyama S, Feng J, Diamond E: The early effect of the Roux-en-Y gastric bypass on hormones involved in body weight regulation and glucose metabolism. Ann Surg 2004;240: 236-242.

6 Bueter M, Lowenstein C, Olbers T, Wang M, Cluny NL, Bloom SR, Sharkey KA, Lutz TA, le Roux CW: Gastric bypass increases energy expenditure in rats. Gastroenterology 2010;138:1845-1853.

7 Nestoridi E, Kvas S, Kucharczyk J, Stylopoulos N: Resting energy expenditure and energetic cost of feeding are augmented after Roux-en-Y gastric bypass in obese mice. Endocrinology 2012;153:2234-2244.

8 Stylopoulos N, Hoppin AG, Kaplan LM: Roux-en-Y gastric bypass enhances energy expenditure and extends lifespan in diet-induced obese rats. Obesity (Silver Spring) 2009;17:1839-1847.

9 Thaler JP, Cummings DE: Minireview: Hormonal and metabolic mechanisms of diabetes remission after gastrointestinal surgery. Endocrinology 2009;150:2518-2525.

10 Defronzo RA: Banting lecture. From the triumvirate to the ominous octet: A new paradigm for the treatment of type 2 diabetes mellitus. Diabetes 2009;58:773-795.

11 Ozcan L, Xu X, Deng SX, Ghorphade DS, Thomas T, Cremers S, Hubbard B, Serrano-Wu MH, Gaestel M, Landry DW, Tabas I: Treatment of obese insulin-resistant mice with an allosteric MAPKAPK2/3 inhibitor lowers blood glucose and improves insulin sensitivity. Diabetes 2015;64:3396-3405.

12 He B, Chen L, Yu C, Piao D, Wang Y, Han P: Roux-en-Y gastric bypass increases hepatic and peripheral insulin sensitivity in rats with type 2 diabetes mellitus. Surg Obes Relat Dis 2014;10:485-493. 
Mu et al.: Roux-en-Y Gastric Bypass Improves Hepatic Glucose Metabolism Involving

Down-Regulation of Protein Tyrosine Phosphatase 1B in Obese Rats

13 Wu S, Tang JC, Zou H, Yan HT, Chen T, Li DX, Tang LJ: Influence of gastric bypass surgery on hepatic gluconeogenesis in type 2 diabetic goto kakizaki rats (in Chinese). Zhonghua Wei Chang Wai Ke Za Zhi 2012;15:11421145.

14 Paranjape SA, Chan O, Zhu W, Acharya NK, Rogers AM, Hajnal A, Sherwin RS: Improvement in hepatic insulin sensitivity after Roux-en-Y gastric bypass in a rat model of obesity is partially mediated via hypothalamic insulin action. Diabetologia 2013;56:2055-2058.

15 Flynn CR, Albaugh VL, Cai S, Cheung-Flynn J, Williams PE, Brucker RM, Bordenstein SR, Guo Y, Wasserman DH, Abumrad NN: Bile diversion to the distal small intestine has comparable metabolic benefits to bariatric surgery. Nature Commun 2015;6:7715.

16 Brunet A, Bonni A, Zigmond MJ, Lin MZ, Juo P, Hu LS, Anderson MJ, Arden KC, Blenis J, Greenberg ME: Akt promotes cell survival by phosphorylating and inhibiting a forkhead transcription factor. Cell 1999;96:857868.

17 Zhang W, Patil S, Chauhan B, Guo S, Powell DR, Le J, Klotsas A, Matika R, Xiao X, Franks R, Heidenreich KA, Sajan MP, Farese RV, Stolz DB, Tso P, Koo SH, Montminy M, Unterman TG: Foxo1 regulates multiple metabolic pathways in the liver: effects on gluconeogenic, glycolytic, and lipogenic gene expression. J Biol Chem 2006; 281:10105-10117.

18 Sajan MP, Ivey RA, Lee MC, Farese RV: Hepatic insulin resistance in ob/ob mice involves increases in ceramide, aPKC activity, and selective impairment of Akt-dependent Foxo1 phosphorylation. J Lipid Res 2015;56:70-80.

19 Puigserver P, Rhee J, Donovan J, Walkey CJ, Yoon JC, Oriente F, Kitamura Y, Altomonte J, Dong H, Accili D, Spiegelman BM: Insulin-regulated hepatic gluconeogenesis through FOX01-PGC-1alpha interaction. Nature 2003; 423:550-555.

20 Bakke J, Haj FG: Protein-tyrosine phosphatase 1b substrates and metabolic regulation. Semin Cell Dev Biol 2015;37:58-65.

21 Egawa K, Maegawa H, Shimizu S, Morino K, Nishio Y, Bryer-Ash M, Cheung AT, Kolls JK, Kikkawa R, Kashiwagi A: Protein-tyrosine phosphatase-1b negatively regulates insulin signaling in 16 myocytes and FAO hepatoma cells. J Biol Chem 2001;276:10207-10211.

22 Elchebly M, Payette P, Michaliszyn E, Cromlish W, Collins S, Loy AL, Normandin D, Cheng A, Himms-Hagen J, Chan CC, Ramachandran C, Gresser MJ, Tremblay ML, Kennedy BP: Increased insulin sensitivity and obesity resistance in mice lacking the protein tyrosine phosphatase-1b gene. Science 1999;283:1544-1548.

23 Mnafgui K, Derbali A, Sayadi S, Gharsallah N, Elfeki A, Allouche N: Anti-obesity and cardioprotective effects of cinnamic acid in high fat diet- induced obese rats. J Food Sci Technol 2015;52:4369-4377.

24 Bueter M, Abegg K, Seyfried F, Lutz TA, le Roux CW: Roux-en-Y gastric bypass operation in rats. J Vis Exp 2012; 64:e3940.

25 Matthews DR, Hosker JP, Rudenski AS, Naylor BA, Treacher DF, Turner RC: Homeostasis model assessment: insulin resistance and beta-cell function from fasting plasma glucose and insulin concentrations in man. Diabetologia 1985;28:412-419.

26 Ip W, Shao W, Chiang YT, Jin T: GLP-1-derived nonapeptide GLP-1(28-36)amide represses hepatic gluconeogenic gene expression and improves pyruvate tolerance in high-fat diet-fed mice. Am J Physiol Endocrinol Metab 2013;305:E1348-1358.

27 Castagneto M, Mingrone G: The effect of gastrointestinal surgery on insulin resistance and insulin secretion. Curr Atheroscler Rep 2012;14:624-630.

28 Ahmad F, Li PM, Meyerovitch J, Goldstein BJ: Osmotic loading of neutralizing antibodies demonstrates a role for protein-tyrosine phosphatase $1 \mathrm{~b}$ in negative regulation of the insulin action pathway. J Biol Chem 1995; 270:20503-20508.

29 Cicirelli MF, Tonks NK, Diltz CD, Weiel JE, Fischer EH, Krebs EG: Microinjection of a protein-tyrosine-phosphatase inhibits insulin action in Xenopus oocytes. Proc Natl Acad Sci U S A 1990;87:5514-5518.

30 Meshkani R, Taghikhani M, Al-Kateb H, Larijani B, Khatami S, Sidiropoulos GK, Hegele RA, Adeli K: Polymorphisms within the protein tyrosine phosphatase $1 \mathrm{~b}$ (PTPN1) gene promoter: functional characterization and association with type 2 diabetes and related metabolic traits. Clin Chem 2007;53:1585-1592.

31 Tiganis T: PTP1B and TCPTP-nonredundant phosphatases in insulin signaling and glucose homeostasis. FEBS J 2013;280:445-458.

32 Shepherd PR, Withers DJ, Siddle K: Phosphoinositide 3-kinase: the key switch mechanism in insulin signalling. Biochem J 1998;333:471-490.

33 Shah M, Law JH, Micheletto F, Sathananthan M, Dalla Man C, Cobelli C, Rizza RA, Camilleri M, Zinsmeister AR, Vella A: Contribution of endogenous glucagon-like peptide 1 to glucose metabolism after Roux-en-Y gastric bypass. Diabetes 2014;63:483-493.

34 Sun D, Wang K, Yan Z, Zhang G, Liu S, Liu F, Hu C, Hu S: Duodenal-jejunal bypass surgery up-regulates the expression of the hepatic insulin signaling proteins and the key regulatory enzymes of intestinal gluconeogenesis in diabetic Goto-Kakizaki rats. Obes Surg 2013;23:1734-1742.

35 Gerhard GS, Styer AM, Wood GC, Roesch SL, Petrick AT, Gabrielsen J, Strodel WE, Still CD, Argyropoulos G: A role for fibroblast growth factor 19 and bile acids in diabetes remission after Roux-en-Y gastric bypass. Diabetes Care 2013;36:1859-1864. 
Mu et al.: Roux-en-Y Gastric Bypass Improves Hepatic Glucose Metabolism Involving Down-Regulation of Protein Tyrosine Phosphatase 1B in Obese Rats

36 Klaman LD, Boss O, Peroni OD, Kim JK, Martino JL, Zabolotny JM, Moghal N, Lubkin M, Kim YB, Sharpe AH, Stricker-Krongrad A, Shulman GI, Neel BG, Kahn BB: Increased energy expenditure, decreased adiposity, and tissue-specific insulin sensitivity in protein-tyrosine phosphatase 1b-deficient mice. Mol Cell Biol 2000;20: 5479-5489.

37 Zabolotny JM, Bence-Hanulec KK, Stricker-Krongrad A, Haj F, Wang Y, Minokoshi Y, Kim YB, Elmquist JK, Tartaglia LA, Kahn BB, Neel BG: PTP1B regulates leptin signal transduction in vivo. Dev Cell 2002;2:489-495.

38 Habegger KM, Heppner KM, Amburgy SE, Ottaway N, Holland J, Raver C, Bartley E, Muller TD, Pfluger PT, Berger J, Toure M, Benoit SC, Dimarchi RD, Perez-Tilve D, D’Alessio DA, Seeley RJ, Tschop MH: GLP-1R responsiveness predicts individual gastric bypass efficacy on glucose tolerance in rats. Diabetes 2014;63:505-513.

39 Schirra J, Nicolaus M, Roggel R, Katschinski M, Storr M, Woerle HJ, Goke B: Endogenous glucagon-like peptide 1 controls endocrine pancreatic secretion and antro-pyloro-duodenal motility in humans. Gut 2006;55:243251.

40 Ji W, Chen X, Lv J, Wang M, Ren S, Yuan B, Wang B, Chen L: Liraglutide exerts antidiabetic effect via PTP1B and PI3K/Akt2 signaling pathway in skeletal muscle of KKAy mice. Int J Endocrinol 2014;2014:312452.

41 Kanoski SE, Ong ZY, Fortin SM, Schlessinger ES, Grill HJ: Liraglutide, leptin and their combined effects on feeding: additive intake reduction through common intracellular signalling mechanisms. Diabetes Obes Metab 2015;17:285-293. 